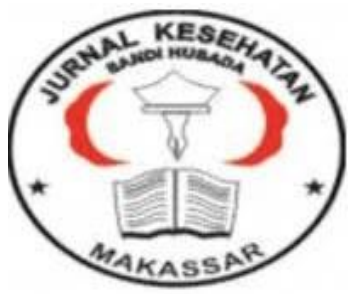

\author{
Jurnal Ilmiah Kesehatan Sandi Husada \\ hhttps://akper-sandikarsa.e-journal.id/JIKSH \\ Volume 9, Nomor 2, Desember 2020, pp 615-624 \\ p-ISSN: 2354-6093 dan e-ISSN: 2654-4563 \\ DOI: $10.35816 /$ jiskh.v10i2.364
}

\title{
Efektivitas Isometric Handgrip Exercise dalam Menurunkan Tekanan Darah pada Pasien Hipertensi
}

Effectiveness Of Isometric Handgrip Exercise In Reducing Blood Pressure In Hypertension Patients

\author{
Ricky Zainuddin ${ }^{1}$, Paramitha Labdullah ${ }^{2}$ \\ 1Program Studi D-III Keperawatan, Akademi Keperawatan Makassar YAPMA \\ 2Program Studi D-III Keperawatan, Akademi Keperawatan Makassar YAPMA

\section{Artikel info}

Artikel history:

Received; Juni 2020

Revised: Juli 2020

Accepted;Juli 2020
Abstrak. Latar belakang: Hipertensi memiliki dampak yang signifikan terhadap kesehatan masyarakat dan telah menjadi beban perawatan kesehatan utama di seluruh dunia. Salah satu terapi non-farmakologis yang dapat diberikan untuk mengurangi tekanan darah pada pasien hipertensi adalah terapi latihan Isometric Handgrip Exercise. Terapi ini telah terbukti mengurangi tekanan darah yang hampir sama dengan latihan aerobik intens. Tinjauan pustaka ini bertujuan untuk menganalisis efek penerapan Latihan Isometrik Handgrip dalam mengurangi tekanan darah pada pasien hipertensi. Metode: Penelitian ini mengeksplorasi bukti kuantitatif yang diterbitkan dalam database elektronik seperti Pubmed, dan Google Cendekia. Dengan menggunakan strategi pencarian, kami mengidentifikasi 16 artikel yang berpotensi dan relevan dengan tujuan penelitian, dan 4 artikel dimasukkan dalam analisis akhir. Hasil: Kita dapat melihat efek yang signifikan pada penurunan tekanan darah sistolik dan diastolik pada kelompok yang diberikan intervensi Latihan Isometrik Handgrip dibandingkan dengan kelompok kontrol. Kesimpulan: Hasil penelitian dari beberapa artikel dalam tinjauan pustaka ini menunjukkan bahwa latihan Latihan Isometrik Handgrip terbukti efektif dalam mengurangi tekanan darah pada pasien hipertensi.

Abstract. Background: Hypertension has a significant impact on public health and has become a major health care burden worldwide. One non-pharmacological therapy that can be given to reduce blood pressure in hypertensive patients is Isometric Handgrip Exercise exercise therapy. This therapy has been shown to reduce blood pressure which is almost the same as intense aerobic exercise. This literature review aims to analyze the effects of the 
application of Isometric Handgrip Exercise in reducing blood pressure in hypertensive patients. Method: This research explores quantitative evidence published in electronic databases such as Pubmed, and Google Scholar. Using a search strategy, we identified 16 articles that were potentially and relevant to the research objectives, and 4 articles were included in the final analysis. Results: We could see a significant effect on systolic and diastolic blood pressure reduction in the group given the Isometric Handgrip Exercise intervention compared with the control group. Conclusion: Research results from several articles in this review literature show that Isometric Handgrip Exercise exercises are proven to be effective in reducing blood pressure in hypertensive patients.

Keywords:

Blood Pressure;

Hypertension;

IsometricHandgripExercise;
Coresponden author:

Email: rickyz.rz22@gmail.com

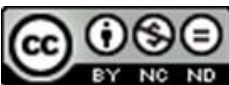

artikel dengan akses terbuka dibawah lisensi BCC BY NC ND-4.0

\section{Pendahuluan}

Tekanan darah menjadi salah satu faktor yang memiliki efek sangat penting dalam sistem sirkulasi. Tinggi atau rendahnya tekanan darah akan mempengaruhi homeostatis di dalam tubuh manusia (Zainuddin et al., 2018) . Pada orang dewasa muda tekanan darah berkisar $120 / 70 \mathrm{mmHg}$ dalam posisi istirahat. Namun secara fisiologis, tekanan darah bervariasi dari waktu ke waktu karena adanya beberapa faktor yang mempengaruhi. Tekanan darah di atas 140/90 mmHg yang diukur pada tiga kesempatan terpisah disebut hipertensi atau tekanan darah tinggi (Stefani, Mascherini, Tosi, \& Galanti, 2019).

Hipertensi memiliki dampak yang signifikan bagi kesehatan masyarakat (Manimala, 2015), dan telah menjadi beban perawatan kesehatan utama di seluruh dunia (Jørgensen, Ryg, Danielsen, Madeleine, \& Andersen, 2018). Hipertensi menjadi penyebab utama kematian ketiga secara global (Ogbutor, Nwangwa, Uyagu, \& Pract, 2019). Hipertensi mempengaruhi lebih dari 1 miliar orang dewasa dan 13\% dari total kematian di seluruh dunia (Farah et al., 2017), (Lam, 2018). Di Amerika, diperkirakan 62\% orang dewasa menderita hipertensi (Manimala, 2015). The Cardiovascular Disease Statistics menunjukkan bahwa prevalensi hipertensi di European Society of Cardiology Country berkisar antara 15,2\% hingga 31,7\% (Timmis et al., 2020), (Lopes, Mesquita-bastos, Alves, \& Ribeiro, 2018). Menurut World Health Organization (WHO), sekitar 972 juta (26,4\%) populasi di seluruh dunia menderita hipertensi dan diperkirakan akan meningkat hingga 29,2\% pada tahun 2025. Dari 972 juta penderita hipertensi, 333 juta tinggal di Negara maju dan 639 juta tinggal di Negara berkembang termasuk Indonesia. Hasil RISKESDAS menunjukkan bahwa prevalensi hipertensi pada penduduk usia $\geq 18$ tahun di Indonesia sebanyak 658.201 kasus (berdasarkan diagnosis dokter sebanyak 8,4\% sedangkan berdasarkan diagnosis dokter atau minum obat sebanyak 8,8\%). Di Provinsi Sulawesi Selatan, kejadian hipertensi sebanyak 21.142 kasus (berdasarkan diagnosis dokter sebanyak 7,2\% sedangkan berdasarkan diagnosis dokter atau minum obat sebanyak 7,8\%) (Kementerian Kesehatan RI, 2019). 
Hipertensi atau tekanan darah tinggi yang tidak terkontrol dapat menyebabkan komplikasi jangka panjang dan berpotensi fatal pada kejadian penyakit arteri koroner, gagal jantung, stroke, dan gagal ginjal. Selain itu, penderita akan mengalami penurunan kognitif dan kualitas hidup yang buruk secara keseluruhan (Ahmed et al., 2019). Oleh karena itu, diperlukan pengelolaan dan penatalaksanaan yang tepat dalam mencegah terjadinya komplikasi penyakit yang lebih parah akibat hipertensi (Nurindra, B.Herman, \& Yenita, 2016). Penatalaksanaan yang tepat yaitu dengan terapi farmakologi dan non farmakologi (Andri, Waluyo, Jumaiyah, \& Nastashia, 2018). Terapi farmakologi dilakukan dengan pemberian obat antihipertensi sebagai pendekatan pengobatan standar untuk mengontrol atau menurunkan tekanan darah. Beberapa jenis obat antihipertensi yang dapat diberikan yaitu diuretik, Beta Bloker, Vasodilator, Calcium Antagonis, AngiotensionConverting Enzyme (ACE) inhibitor dan Angiotensin Receptor Blockers (ARBs) (Ainurrafiq, Risnah, \& Azhar, 2019). Akan tetapi terapi obat tersebut memiliki efek samping yang dikaitkan dengan peningkatan risiko kejadian kardiovaskular, batuk kering, pusing, sakit kepala, dan lemas (Okamoto, Hashimoto, \& Kobayashi, 2019). Pedoman pengobatan Eropa dan AS merekomendasikan modifikasi gaya hidup sebagai terapi non farmakologis, salah satunya adalah peningkatan aktivitas fisik melalui terapi Isometric Handgrip Exercise (Okamoto et al., 2019). American Heart Association (AHA), mengklasifikasikan terapi Isometric Handgrip Exercise sebagai terapi potensial untuk menurunkan tekanan darah pada pasien hipertensi (Silva et al., 2018).

Isometric Handgrip Exercise merupakan terapi latihan statis menggunakan handgrip dynamometer yang melibatkan kontraksi tahanan otot tanpa perubahan panjang otot misalnya mengangkat atau mendorong beban berat dan mengontraksikan otot terhadap benda-benda tertentu (Karthikkeyan, Latha, \& Gokulnathan, 2020), (Susiladewi, Widyanthari, \& Adnyana, 2017), (Parlindungan, Lukitasari, \& Mudatsir, 2016). Latihan dengan intensitas rendah hingga sedang dapat dilakukan di mana saja, karena sangat mudah untuk dilakukan, pralatan yang relatif murah, tidak menimbulkan stres kardiovaskular dan berdurasi pendek (Hamza \& Elden, 2019). Latihan dilakukan dengan kontraksi $4 \times 2$ menit pada 20-50\% MVC (Maximal Voluntary Contraction) dengan istirahat 1-5 menit (Stefani et al., 2019). Terapi ini dapat dilakukan 3-5 kali dalam seminggu dengan durasi 10-20 menit setiap kali latihan (Manimala, 2015).

Terapi latihan Isometric Handgrip Exercise dapat menurunkan tekanan darah pada hipertensi sekitar $7 \mathrm{mmHg}$ untuk sistolik dan $5 \mathrm{mmHg}$ untuk diastolik (Farah et al., 2017), (Mortimer \& Mckune, 2011). Ketika pegangan dilakukan, tubuh menghasilkan stres karena latihan dan sebagai produk sampingan dari tekanan darah diturunkan. Isometric Handgrip Exercise yang merupakan latihan melawan suatu objek sehingga otot-otot menjadi stres tetapi tidak meregang, menyebabkan penurunan tekanan darah yaitu sekitar $3 \mathrm{mmHg}$ (Manimala, 2015). Terapi latihan ini juga dapat meningkatkan disfungsi endotel dengan meningkatkan tegangan yang dimediasi oleh bioavailabilitas dari oksida nitrat dan peningkatan aktivitas antioksidan. Latihan isometrik menghasilkan peningkatan tekanan darah yang signifikan, yang sangat penting dalam mempertahankan perfusi otot selama kontraksi berkelanjutan (Jeelani \& Taklikar, 2018). Keterlibatan massa otot yang lebih kecil selama latihan isometrik (unilateral vs bilateral dan ekstremitas atas dan ekstremitas bawah) menghasilkan penurunan tekanan darah yang lebih tinggi (Lopes et al., 2018). Tekanan darah dan respons detak jantung terhadap latihan isometrik dipengaruhi oleh kekuatan kontraksi, ukuran otot yang berkontraksi dan lamanya waktu yang digunakan (Piikmann \& Reisberg, 2018). 


\section{Metode}

Tinjauan literatur dilakukan melalui pencarian hasil publikasi ilmiah pada rentang tahun 2015-2020 menggunakan database pubmed, dan google scholar. Pada database pubmed dimasukan keyword 1 "blood pressure" didapatkan hasil 815.870 artikel. Keyword 2 "hypertension" ditemukan 546.130 artikel. Keyword 3 "isometric handgrip exercise" ditemukan 2.535 artikel. Kemudian menggabungkan keyword 1,2 dan 3 "((blood pressure) AND hypertension) AND isometric handgrip exercise" ditemukan 853 artikel. Setelah dilakukan pencarian artikel kemudian dilakukan pembatasan jumlah artikel LIMIT publication dates (2015-2020) didapatkan 434 artikel, open acces didapatkan 301 artikel, dan abstract didapatkan 2 artikel.

Sedangkan pencarian melalui data base google scholar dimasukan keyword 1 "blood pressure" didapatkan hasil 4.420 .000 artikel. Keyword 2 "hypertension" didapatkan 3.820.000 artikel. Keyword 3 "isometric handgrip exercise" didapatkan 21.300 artikel. Kemudian menggabungkan keyword 1, 2 dan 3 "blood pressure AND hypertension AND isometric handgrip exercise" ditemukan 10.800 artikel. Selanjutnya dilakukan pembatasan jumlah artikel LIMIT to date (2015-2020) didapatkan 3.320 artikel, berdasarkan relevansi didapatkan 788 artikel. Dari seluruh database dan sumber lain terdapat 157 abstrak dan judul sesuai dengan metode pencarian. Kemudian menghapus beberapa artikel duplikat sehingga tersisa 51 artikel. Judul kemudian disaring untuk melihat relevansi dan kutipan berdasarkan judul tersisa 34 artikel. Dari jumlah tersebut ditemukan 21 artikel yang dianggap berhubungan langsung dengan pertanyaan penelitian dan memiliki teks lengkap untuk ditinjau. Selanjutnya dilakukan peninjauan abstrak dan studi lengkap berdasarkan tujuan penelitian tersisa 16 artikel.

\section{Hasil Dan Pembahasan}

\section{Tekanan Darah}

Tekanan darah merupakan salah satu tanda vital bersama dengan laju pernapasan, denyut jantung, saturasi oksigen, dan suhu tubuh. Tekanan darah istirahat normal pada orang dewasa adalah sekitar 120 milimeter merkuri (16 kPa) sistolik dan 80 milimeter merkuri (11 kPa) diastolik, disingkat "120/80 mmHg". Secara global tekanan darah rata-rata usia yang distandarisasi tetap hampir sama sejak 1975 hingga saat ini sekitar 127/79 mmHg pada pria dan 122/77 mmHg pada wanita (Risk \& Collaboration, 2017).

Tekanan darah dipengaruhi oleh curah jantung, resistensi perifer total serta kekakuan arteri dan bervariasi tergantung pada situasi, keadaan emosi, aktivitas, dan status kesehatan/penyakit relatif. Dalam jangka pendek, tekanan darah diatur oleh baroreseptor yang bertindak melalui otak untuk mempengaruhi sistem saraf dan endokrin. Faktor lain seperti usia dan jenis kelamin dapat mempengaruhi tekanan darah seseorang. Selain itu, perbedaan antara pengukuran tekanan darah lengan kiri dan kanan cenderung kecil. Namun, kadang-kadang ada perbedaan yang konsisten lebih besar dari $10 \mathrm{mmHg}$ yang mungkin perlu diselidiki lebih lanjut, misalnya untuk penyakit arteri perifer atau penyakit arteri obstruktif (Risk \& Collaboration, 2017).

Gangguan kontrol tekanan darah meliputi tekanan darah tinggi, tekanan darah rendah, hipotensi ortostatik, dan tekanan darah yang menunjukkan fluktuasi yang berlebihan atau maladaptive (Stevens et al., 2016). Tekanan arteri biasanya diukur melalui sphygmomanometer yang menggunakan ketinggian kolom merkuri, atau pengukur aneroid, untuk mencerminkan tekanan darah dengan auskultasi. Teknik pengukuran tekanan darah otomatis paling umum didasarkan pada metode osilometrik (Forouzanfar et al., 2015). 


\section{Hipertensi}

Hipertensi adalah penyakit yang disebabkan oleh meningkatnya tekanan darah sistolik $\geq$ $140 \mathrm{mmHg}$ dan tekanan darah diastolik $\geq 90 \mathrm{mmHg}$ yang dilakukan dalam 2 kali pengukuran dengan perbedaan waktu menit dalam kondisi istirahat (Kementerian Kesehatan RI, 2019). Hipertensi jarang disertai dengan gejala dan identifikasi biasanya melalui skrining. Namun, beberapa orang yang mengalami hipertensi atau tekanan darah tinggi melaporkan sakit kepala (terutama di bagian belakang kepala dan di pagi hari), serta sakit kepala ringan, vertigo, tinitus (berdengung atau mendesis di telinga), penglihatan kabur atau berkunang-kunang dan mudah lemah (Williams et al., 2018). Pada pemeriksaan fisik, hipertensi dapat dikaitkan dengan adanya perubahan fundus optik yang terlihat oleh ophthalmoscopy. Tingkat keparahan perubahan khas retinopati hipertensi dinilai dari I ke IV; kelas I dan II agak sulit dibedakan. Tingkat keparahan retinopati berkorelasi secara kasar dengan durasi atau tingkat keparahan hipertensi (Dinicolantonio, Mehta, \& Keefe, 2017).

Sekitar $90-95 \%$ adalah kasus primer, didefinisikan sebagai tekanan darah tinggi karena gaya hidup yang tidak spesifik dan faktor genetik. Beberapa faktor risiko yang dapat meningkatkan prevalensi hipertensi termasuk pertumbuhan populasi, peningkatan usia dan faktor risiko perilaku, seperti pola makan yang tidak sehat, kelebihan garam dalam diet, penggunaan tembakau, konsumsi alkohol, kelebihan berat badan, paparan stres persisten, kolesterol tinggi, diabetes mellitus, dan kurangnya aktivitas fisik. Sedangkan 5$10 \%$ adalah kasus sekunder dari penyebab yang dapat diidentifikasi seperti penyakit ginjal kronis, gangguan endokrin, kehamilan (Karthikkeyan et al., 2020), (Ji, Zheng, Zhang, $\mathrm{Wu}, \&$ Zhao, 2018).

\section{Isometric Handgrip Exercise}

Isometric Handgrip Exercise merupakan salah satu bentuk latihan statis menggunakan handgrip dynamometer yang melibatkan kontraksi statis otot tanpa gerakan terlihat di sudut sendi dan tidak menyebabkan perubahan pada panjang otot dan sudut sendi, meskipun kekuatan kontraksi dapat bervariasi (Millar, Mcgowan, \& Swaine, 2014). Handgrip merupakan alat yang biasa digunakan untuk mengukur kekuatan otot genggaman tangan dilakukan dengan meremas perangkat genggam kecil (Manimala, 2015).

Latihan isometrik atau statis melibatkan kontraksi otot rangka tanpa perubahan panjang otot, misalnya mengangkat atau mendorong beban berat dan mengontraksikan otot terhadap benda-benda tertentu, berbeda dengan latihan isotonik atau dinamis dimana kontraksi otot rangka menyebabkan perubahan panjang otot seperti berlari, berenang. Latihan isometrik dapat mempertahankan tekanan darah yang diinginkan pada individu dengan ketidakmampuan untuk melakukan latihan isotonik. Selain itu, latihan ini juga dapat meningkatkan disfungsi endotel dengan meningkatkan tegangan yang dimediasi oleh bioavailabilitas dari oksida nitrat dan peningkatan aktivitas antioksidan.

Biasanya selama latihan, ada peningkatan konsentrasi metabolit seperti asam laktat dan adenosin yang terdeteksi oleh ujung saraf metabolit-sensitif dalam interstitium otot rangka. Zat-zat ini meningkatkan pelepasan serat aferen kelompok IV (metaboreseptor), memicu refleks kuat yang meningkatkan aktivitas saraf simpatis. Hal ini menyebabkan vasokonstriksi, yang berkontribusi terhadap peningkatan tekanan darah. Dengan pelatihan olahraga teratur, terjadi peningkatan kepadatan kapiler, meningkatkan densitas mitokondria, aktivasi enzim oksidatif, dan peningkatan 0 2ekstraksi di otot rangka. Increased aliran pembuluh darah, bersama dengan peningkatan kemampuan otot yang terlatih untuk mempertahankan metabolisme aerobik, menurunkan interstitial 
konsentrasi metabolit, menyebabkan lebih sedikit stimulasi metaboreseptor, sehingga membangkitkan respons simpatik yang lebih kecil, menyebabkan lebih sedikit peningkatan tekanan darah. Selama pelatihan isometrik, refleks kemoreseptor yang bertanggung jawab untuk aktivitas saraf simpatik berkurang dan dengan demikian menyebabkan pelemahan respon saraf simpatis terhadap aktivitas saraf simpatik yang bertanggung jawab untuk penurunan tekanan darah istirahat selama periode waktu. Tekanan darah dan respons detak jantung terhadap latihan isometrik dipengaruhi oleh kekuatan kontraksi, ukuran otot yang berkontraksi dan lamanya waktu yang dikontrak (Garg, Malhotra, Kumar, Dhar, \& Tripathi, 2014).

Latihan Isometric Handgrip Exercise mengaktifkan reseptor mekanik segera, karena meningkatnya ketegangan otot. Hal ini terjadi dengan mempertahankan ketegangan otot, meningkatkan keadaan eksitasi sistem saraf pusat dan menghasilkan kemungkinan peningkatan aliran simpatis dan penurunan aliran parasimpatis, sehingga terjadi peningkatan respons tekanan darah. Respons tekanan terhadap latihan isometrik berasal dari refleks yang berfungsi untuk meningkatkan tekanan perfusi ke otot-otot aktif, di mana aliran darah terhambat oleh kontraksi otot yang berkelanjutan (Garg, Malhotra, Dhar, \& Tripathi, 2013). Keterlibatan massa otot yang lebih kecil selama latihan isometrik (unilateral vs bilateral dan ekstremitas atas dan ekstremitas bawah) menghasilkan penurunan tekanan darah yang lebih tinggi (Lopes et al., 2018).

Isometric Handgrip Exercise telah terbukti dapat menurunkan tekanan darah yang hampir sama dengan latihan aerobik yang intens. Selain itu, latihan ini juga dapat mencegah terjadinya atrofi pada otot, meningkatkan volume otot, stabilitas sendi dan mengurangi edema (Manimala, 2015).

Hasil penelitian yang dilakukan oleh (Carlson et al., 2016) bertujuan untuk mengetahui efektifitas isometric handgrip exercise dalam menurunkan tekanan darah pada pasien hipertensi di Armidale, NSW, Australia, pada 40 responden $(20$ kelompok 30\% MVC dan (20 kelompok 5\% MVC). Penelitian ini merupakan jenis penelitian kuantitatif randomized controlled trial menggunakan rancangan quasi experimental (pretest-posttest with control group). Hasil penelitian menunjukkan penurunan tekanan darah sistolik $7 \mathrm{mmHg}$ $(136 \pm 12$ menjadi $129 \pm 15 ; \mathrm{P}=0,04)$ dan penurunan $4 \mathrm{mmHg}$ tekanan arterial rata-rata (100 \pm 8 hingga $96 \pm 11 ; \mathrm{P}=0,04)$ pada kelompok intervensi $30 \%$, sedangkan pada kelompok kontrol 5\% tidak ada pengurangan yang signifikan secara statistik pada tekanan darah diastolik, sehingga disimpulkan bahwa pelatihan resistensi isometrik yang dilakukan dengan menggunakan latihan handgrip pada 30\% dari kontraksi sukarela maksimum secara signifikan mengurangi tekanan darah sistolik dan diastolik.

Hasil penelitian (Rahmawati, Dewi, \& Sari, 2017) bertujuan untuk mengetahui perbandingan isometric handgrip exercise dan jalan kaki terhadap tekanan darah sistolik dan tekanan darah diastolik pada pasien hipertensi di Wilayah Kerja Puskesmas Pohjarak Kabupaten Kediri Prov Jawa Timur, dengan jumlah sampel sebanyak 44 responden (22 kelompok isometric handgrip exercise, dan 22 kelompok jalan kaki). Penelitian ini merupakan jenis penelitian kuantitatif menggunakan rancangan quasi experimental (two group pretest posttest). Hasil penelitian menunjukkan bahwa terjadi penurunan tekanan darah sistolik $(\mathrm{p}=0,026)$, dan tekanan darah diastolik $(\mathrm{p}=0,031)$, dengan selisih rerata penurunan tekanan darah sistolik 8,82 $\mathrm{mmHg}$, dan pada tekanan darah diastolik 8,40 $\mathrm{mmHg}$, sehingga disimpulkan bahwalatihan isometric handgrip exercise dan jalan kaki dapat menurunkan tekanan darah sistolik dan tekanan darah diastolik pada pasien hipertensi. 
Hasil penelitian (Andri et al., 2018) bertujuan untuk mengidentifikasi efektifitas isometric handgrip exercise dan slow deep breathing exercise terhadap perubahan tekanan darah pada penderita hipertensi di Puskemas Pasar Kepahiang dan Puskesmas Bukit Sari Prov Bengkulu, dengan jumlah sampel sebanyak 32 responden (16 kelompok isometric handgrip exercise, dan 16 kelompok slow deep breathing exercise). Penelitian ini merupakan jenis penelitian kuantitatif menggunakan rancangan quasi experimental (two group pretest posttest). Hasil penelitian menunjukkan bahwa ada perubahan tekanan darah sistolik dan diastolik setelah dilakukan intervensi isometric handgrip exercise $(t=8,279, p=0,000),(t=6,154, p=0,000)$, serta terjadi perubahan tekanan darah sistolik dan diastolik setelah diberikan intervensi slow deep breathing exercise $(t=3,632, p=0,002)$, $(\mathrm{t}=4,226, \mathrm{p}=0,001)$.

Penelitian terbaru dilakukan oleh (Ogbutor et al., 2019) bertujuan untuk menilai efek isometric handgrip exercise dalam menurunkan tekanan darah pada pasien hipertensi di Pusat Medis Federal Benin Teaching Hospital Nigeria, dengan jumlah sampel sebanyak 400 responden (200 kelompok intervensi dan 200 kelompok kontrol). Penelitian ini merupakan jenis penelitian kuantitatif randomized controlled trial menggunakan rancangan quasi experimental (pretest-posttest with control group). Hasil penelitian menunjukkan penurunan rata-rata tekanan darah sistolik dan tekanan darah diastolik pada kelompok intervensi masing-masing sebesar 7,48 $\pm 0,06 \mathrm{mmHg}$ dan 6,41 $\pm 1,01$ $\mathrm{mmHg}$, dan secara signifikan tekanan darah sistolik, diastolik dan denyut nadi meningkat dalam 5 menit setelah latihan pada 30\% MVC dengan nilai rata-rata 8,60 $\pm 0,20 \mathrm{mmHg}$, 7,33 $\pm 0,03 \mathrm{mmHg}$, dan 8,24 $\pm 0,20$ denyut /menit.

\section{Simpulan Dan Saran}

Berdasarkan pada beberapa hasil penelitian dalam literature review ini terlihat bahwa latihan Isometric Handgrip Exercise terbukti efektif menurunkan tekanan darah pada pasien hipertensi. Diharapkan kepada pihak institusi agar dapat memfasilitasi petugas pelayanan khususnya perawat, dengan memberikan pelatihan untuk meningkatkan pengetahuan dan keterampilan mengenai terapi latihan untuk pasien hipertensi khususnya latihan Isometric Handgrip Exercise.

\section{Daftar Rujukan}

Ahmed, Y. R., Sc, M., Hanfy, H. M., Ph, D., Kamal, W. M., \& Ph, D. (2019). The Effect of Isometric Hand Grip on Blood Pressure in Post Menopausal Hypertension. Med. J. Cairo Univ, 87(5), 2685-2691. https://doi.org/10.21608/MJCU.2019.58501

Ainurrafiq, Risnah, \& Azhar, M. U. (2019). Terapi Non Farmakologi dalam Pengendalian Tekanan Darah Pada Pasien Hipertensi: Systematic Review. The Indonesian Journal of Health Promotion, 2(3), 192-199. https://doi.org/https://doi.org/10.31934/mppki.v2i3

Andri, J., Waluyo, A., Jumaiyah, W., \& Nastashia, D. (2018). Efektivitas Isometric Handgrip Exercise Dan Slow Deep Breathing Exercise Terhadap Perubahan Tekanan Darah Pada Penderita Hipertensi. Jurnal Keperawatan Silampari, 2(1), 371-384. https://doi.org/https://doi.org/10.31539/jks.v2i1.382

Carlson, D. J., Inder, J., Palanisamy, S. K. A., Mcfarlane, J. R., Dieberg, G., \& Smart, N. A. (2016). The Efficacy of Isometric Resistance Training Utilizing Handgrip Exercise For Blood Pressure Management A Randomized Trial. Journal Medicine (Baltimore), 95(52), 1-7. https://doi.org/10.1097/MD.0000000000005791

Dinicolantonio, J. J., Mehta, V., \& Keefe, J. H. O. (2017). Is Salt a Culprit or an Innocent Bystander in Hypertension? A Hypothesis Challenging the Ancient Paradigm. The 
American Journal of $\quad$ Medicine, 130(8), 893-899. https://doi.org/10.1016/j.amjmed.2017.03.011

Farah, B. Q., Germano-soares, A. H., Rodrigues, S. L. C., Santos, C. X., Barbosa, S. S., Vianna, L. C., ... Ritti-dias, R. M. (2017). Acute and Chronic Effects of Isometric Handgrip Exercise on Cardiovascular Variables in Hypertensive Patients: A Systematic Review. Journal Sports, 5(3), 1-10. https://doi.org/10.3390/sports5030055

Forouzanfar, M., Dajani, H. R., Groza, V. Z., Bolic, M., Rajan, S., \& Batkin, I. (2015). Oscillometric Blood Pressure Estimation: Past, Present, and Future. EEE Reviews in Biomedical Engineering, 8(3), 1-19. https://doi.org/10.1109/RBME.2015.2434215

Garg, R., Malhotra, V., Dhar, U., \& Tripathi, Y. (2013). The Isometric Handgrip Exercise As a Test for Unmasking Hypertension in the Offsprings of Hypertensive Parents. Journal of Clinical and Diagnostic Research, 7(6), 996-999. https://doi.org/10.7860/JCDR/2013/5094.3043

Garg, R., Malhotra, V., Kumar, A., Dhar, U., \& Tripathi, Y. (2014). Effect of Isometric Handgrip Exercise Training on Resting Blood Pressure in Normal Healthy Adults. Journal of Clinical and Diagnostic Research, 8(9), 10-12. https://doi.org/10.7860/JCDR/2014/8908.4850

Hamza, F. A., \& Elden, A. R. E. (2019). The Effect Of Handgrip Exercises On Blood Pressure. Global Scientific Journal, 7(8), 1448-1457. https://doi.org/ISSN 2320-9186

Jeelani, M., \& Taklikar, R. H. (2018). Isometric Exercise And Its Effect On Blood Pressure And Heart Rate; A Comparative Study Between Healthy, Young, And Elderly Males In And Around Raichur City. International Journal of Scientific Study, 6(6), 12-16. https://doi.org/10.17354/ijss/2018/103

Ji, C., Zheng, L., Zhang, R., Wu, Q., \& Zhao, Y. (2018). Handgrip Strength Is Positively Related To Blood Pressure And Hypertension Risk: Results From The National Health And Nutrition Examination Survey. BMC Medical Research Methodology, 17(86), 1-7. https://doi.org/https://doi.org/10.1186/s12944-018-0734-4

Jørgensen, M. G., Ryg, J., Danielsen, M. B., Madeleine, P., \& Andersen, S. (2018). Twenty Weeks Of Isometric Handgrip Home Training To Lower Blood Pressure In Hypertensive Older Adults: A Study Protocol For A Randomized Controlled Trial. BMC Medical Central, 19(97), 1-7. https://doi.org/10.1186/s13063-018-2441-x

Karthikkeyan, K., Latha, K., \& Gokulnathan, V. (2020). Effects of Isometric Handgrip Exercise on Blood Pressure and its Role in Identifying Hypertensive Risk Individuals. International Journal of Contemporary Medical Research, 7(2), 1-4. https://doi.org/http://dx.doi.org/10.21276/ijcmr.2020.7.2.4

Lam, E. T. C. (2018). The Benefits of Isometric Hand Grip Devices. Research \& Investigations in Sports Medicine, 1(5), 73-74. https://doi.org/10.31031/RISM.2018.01.000521

Lopes, S., Mesquita-bastos, J., Alves, A. J., \& Ribeiro, F. (2018). Exercise As A Tool For Hypertension And Resistant Hypertension Management: Current Insights. Integrated Blood Pressure Control, 11(18), 65-71. https://doi.org/10.2147/IBPC.S136028

Manimala, J. (2015). Efficacy of Isometric Hand Grip Training to Lower Resting Blood Pressure : A Systematic Review and Meta - Analysis. American College of Sports Medicine, 14(7), 1-20.

Millar, P. J., Mcgowan, C. L., \& Swaine, I. L. (2014). Evidence for the Role of Isometric Exercise Training in Reducing Blood Pressure : Potential Mechanisms and Future Directions. Sports Medicine, 44(3), 345-356. https://doi.org/10.1007/s40279013-0118-x 
Mortimer, J., \& Mckune, A. J. (2011). Effect Of Short-Term Isometric Handgrip Training On Blood Pressure In Middle-Aged Females. Africa Cardiovascular Journal of Africa, 22(5), 257-260. https://doi.org/10.5830/CVJA-2010-090

Nurindra, M. Y. S., B.Herman, R., \& Yenita. (2016). Perbandingan Tekanan Darah Sebelum dan Sewaktu Melakukan Handgrip Isometric Exercise pada Mahasiswa Angkatan 2011 Fakultas Kedokteran Universitas Andalas. Jurnal Kesehatan Andalas, 5(2), 443-447.

Ogbutor, G., Nwangwa, E., Uyagu, D., \& Pract, N. J. C. (2019). Isometric Handgrip Exercise Training Attenuates Blood Pressure in Prehypertensive Subjects at 30\% Maximum Voluntary Contraction. Nigerian Journal of Clinical Practice, 22(12), 1765-1771. https://doi.org/10.4103/njcp.njcp

Okamoto, T., Hashimoto, Y., \& Kobayashi, R. (2019). Isometric Handgrip Training Reduces Blood Pressure And Wave Reflections In East Asian, Non-Medicated, Middle-Aged And Older Adults: A Randomized Control Trial. Aging Clinical and Experimental Research, 7(1), 1-7. https://doi.org/10.1007/s40520-019-01330-3

Parlindungan, T., Lukitasari, A., \& Mudatsir. (2016). Latihan Isometrik Bermanfaat Menurunkan Tekanan Darah Pada Penderita Hipertensi. Jurnal Ilmu Keperawatan, 4(1), 71-81. https://doi.org/ISSN : 2338-6371

Piikmann, S., \& Reisberg, K. (2018). The Effect of Isometric Handgrip Training On Blood Pressure. Acta Kinesiologiae Universitatis Tartuensis, 24, 109-120. https://doi.org/https://doi.org/10.12697/akut.2018.24.08

Rahmawati, E., Dewi, A., \& Sari, N. K. (2017). Perbandingan Isometric Handgrip Exercise Dan Jalan Kaki Terhadap Tekanan Darah Sistolik Dan Tekanan Darah Diastolik Pada Pasien Hipertensi Di Wilayah Puskesmas Pohjarak Kabupaten Kediri. Universitas Muhammadiyah Yogyakata.

RI, K. K. (2019). Laporan Nasional RISKESDAS 2018. Jakarta: Badan Penelitian dan Pengembangan Kesehatan. https://doi.org/9786023731189

Risk, N. C. D., \& Collaboration, F. (2017). Worldwide Trends In Blood Pressure From 1975 To 2015: A Pooled Analysis Of 1479 Population-Based Measurement Studies With 19 - 1 Million Participants. The Lancet, 389(10064), 37-55. https://doi.org/10.1016/S0140-6736(16)31919-5

Silva, G. O., Farah, B. Q., Germano-Soares, A. H., Andrade-Lima, A., Santana, F. S., Rodrigues, S. rgio L. C., \& Ritti-Dias, R. M. (2018). Acute Blood Pressure Responses After Different Isometric Handgrip Protocols In Hypertensive Patients. Journal Clinics, 17(10), 1-6. https://doi.org/10.6061/clinics/2018/e373

Stefani, L., Mascherini, G., Tosi, B., \& Galanti, G. (2019). Hypertension Today: Role of Sports and Exercise Medicine. Journal Of Hypertension And Cardiology, 2(4), 20-27. https://doi.org/10.14302/issn.2329

Stevens, S. L., Wood, S., Koshiaris, C., Law, K., Glasziou, P., Stevens, R. J., \& Mcmanus, R. J. (2016). Blood Pressure Variability And Cardiovascular Disease: Systematic Review And Meta-Analysis. BMJ Clinical Researh, 354(4098), 14-16. https://doi.org/10.1136/bmj.i4098

Susiladewi, I. A. M. V., Widyanthari, D. M., \& Adnyana, I. M. O. (2017). Pengaruh Latihan Isometrik Terhadap Tekanan Darah Pasien Hipertensi. Community of Publishing in Nursing (COPING), 5(3), 153-160. https://doi.org/ISSN: 2303-1298

Timmis, A., Group, W., Townsend, N., Gale, C. P., Torbica, A., Lettino, M., ... Vardas, P. (2020). European Society of Cardiology: Cardiovascular Disease Statistics 2019. European Heart Journal, 44(41), 12-85. https://doi.org/10.1093/eurheartj/ehz859

Williams, B., Mancia, G., Spiering, W., Rosei, E. A., Azizi, M., Burnier, M., ... Desormais, I. (2018). 2018 ESC/ESH Guidelines For The Management Of Arterial Hypertension. 
European Heart Journal, 39(33), 3021-3104. https://doi.org/10.1097/HJH.

Zainuddin, R., Aliwu, A. F., Rachmawaty, R., Syam, Y., Program, M., Magister, S., ... Makassar, U. H. (2018). Efektivitas Progressive Muscle Relaxation terhadap Tekanan Darah pada Penyakit Hipertensi, 7(2), 42-46. https://doi.org/10.30994/sjik.v7i2.169 